\title{
UNUSUAL CASE OF VAN DER KNAAP'S DISEASE PRESENTING AT 2 YEARS OF AGE FOLLOWING HEAD TRAUMA
}

Ishaan Jani ${ }^{1}$, V. D. Aironi², Ashutosh Chitnis ${ }^{3}$, Priti Kapoor ${ }^{4}$, Abhay Gursale ${ }^{5}$

\section{HOW TO CITE THIS ARTICLE:}

Ishaan Jani, V. D. Aironi, Ashutosh Chitnis, Priti Kapoor, Abhay Gursale. "Unusual case of Van Der Knaap's disease presenting at 2 years of age following head trauma". Journal of Evolution of Medical and Dental Sciences 2015; Vol. 4, Issue 60, July 27; Page: 10568-10572, D0I: 10.14260/jemds/2015/1525

ABSTRACT: Megaloencephalic leucoencephalopathy with subcortical cysts (MLC) (Van Der Knaap Disease) is an entity of neurodegenerative disease characterized by infantile-onset megalencephaly, cerebral leukoencephalopathy, and a delayed on set of slowly progressive neurologic dysfunction. MLC is distinguished from other leucoencephalopathies by its remarkably slow course of neurologic deterioration. Infantile onset macrocephaly is characteristic. Age of onset varies from birth to 25 years, with median age of 6 months.[1] We report a case of 23 months old male child with a history of fall followed by an episode of seizure and vomiting. The patient underwent a non-contrast CT scan that showed prominent bilateral cortical hypodense white matter. Further imaging with MRI was indicated to rule out white matter disease.

KEYWORDS: Megaloencephalic Leucoencephalopathy, Van Der Knapp's disease, Infantile onset megalencephaly.

INTRODUCTION: MLC is a rare autosomal recessive disorder with a variable but mild clinical course. MLC is a genetically heterogeneous disorder with approximately $75 \%$ cases caused by mutation of MLC1 gene. This gene is located in astrocyte-astrocyte junction. A newly described mutation in HEPACAM gene, which encodes for Glial CAM proteins may account for the remaining cases. Both these defects result in abnormal cell junction trafficking. HEPACAM mutations result in a spectrum of abnormalities ranging from benign familial macrocephaly to MLC.[1] The above-mentioned case showed predominant features corresponding to MLC1 mutation.

CASE REPORT: A 23 months old boy resident of Navi Mumbai of second degree consanguineous marriage presented with complaints of 1 episode of seizure and vomiting following a history of fall. The seizure was associated with involution of all 4 limbs, which was followed by 1 episode of nonfoul smelling, and non-blood stained vomiting. On examination, the child was found to have a big head with head circumference of $55.4 \mathrm{~cm}$. The patient had a history of frequent falls in the past. Delayed milestones in the form of inability to walk without support at 23 months of age. Patient has unremarkable birth history and immunization history. On general and systemic examination patient was conscious co-operative and found to have pallor, power of 3/5 in both upper and lower limbs. Reflexes were normal.

Non-contrast CT scan was performed which showed prominent hypodense white matter in all the lobes of brain (Figures 1, 2, 3 \& 4). No evidence of any hemorrhage or space-occupying lesion seen, persistent cavum septum pellucidum (Figures $2 \& 3$ ) was noted and ventricular system was unremarkable. 


\section{CASE REPORT}

Fig. 1: Axial CT at the level of midbrain shows marked hypodensity of cortical white matter with sparing of the midbrain and cerebellar white matter.

Fig. 2: Axial CT at the level of basal ganglia shows marked hypodensity of the cortical white matter, the cortical and deep gray matter is however normal in appearance.

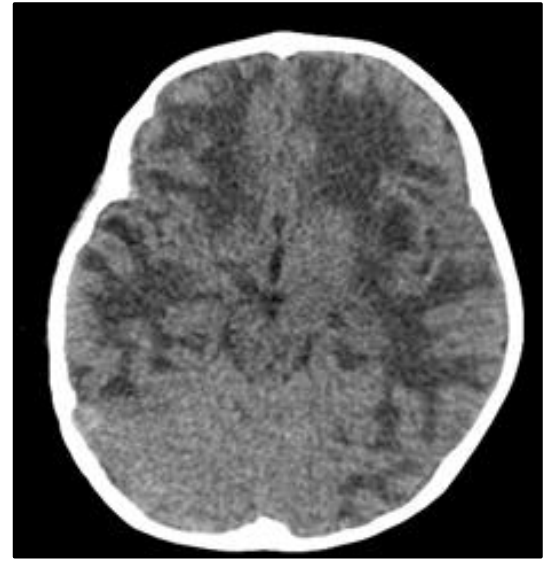

Fig. 1

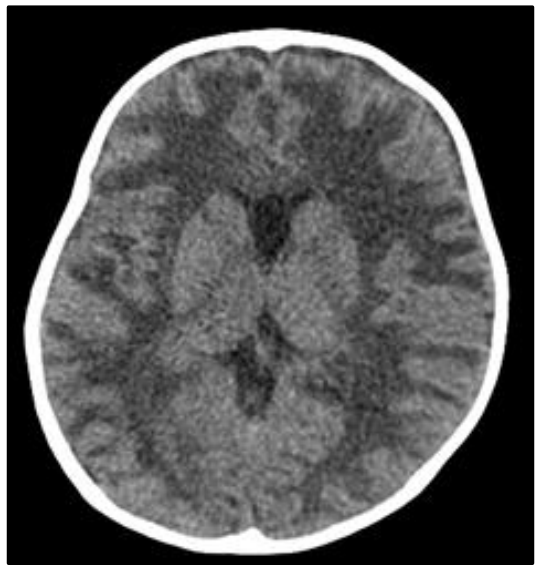

Fig. 2

Fig. 3: Axial CT at the level of body of lateral ventricles shows the diffuse marked cortical white matter hypodensity and a persistent cavum septum pellucidum.

Fig. 4: Axial CT at the level of centrum semiovale shows the diffuse hypodense cortical white matter.

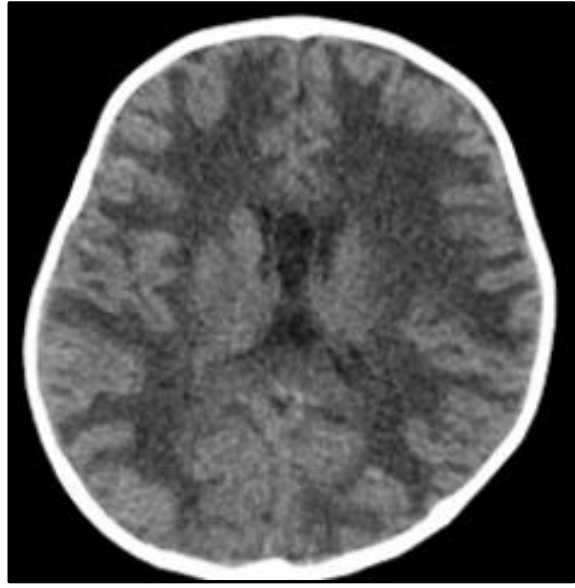

Fig. 3

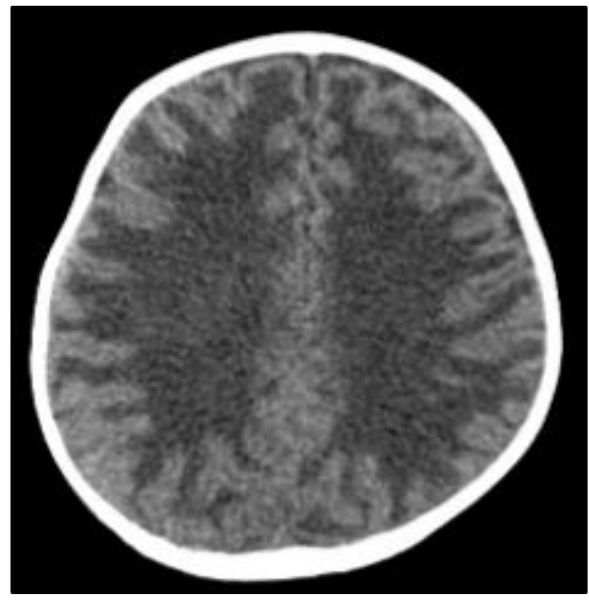

Fig. 4

In view of prominent hypodense white matter not corresponding with the normal myelination pattern of 23 months old child, further evaluation with non-contrast MRI was done. MRI T1 weighted sagittal images showed hypointensity in sub-cortical and deep white matter with sparing of corpus callosum, brain stem and cerebellum (Figure 5). T2 weighted axial images showed diffuse hyperintensity in cortical white matter with normal grade 5 gyration and characteristic watery and swollen appearance of white matter (Figures 6, 7 \& 8). FLAIR axial images showed small well defined ovoid cystic lesions, which followed CSF intensity in all sequences in sub cortical white matter of bilateral anterior temporal lobes (Figures $9 \& 10$ ). 


\section{CASE REPORT}

Fig. 5: Mid-sagittal T1WI shows the abnormal hypointense cortical white matter and the normal hyperintense white matter in corpus callosum, brain stem and cerebellum.

Fig. 6: Axial T2WI at the level of pons shows the increased hyperintensity of the temporal lobe white matter with sparing of the pons and cerebellum.

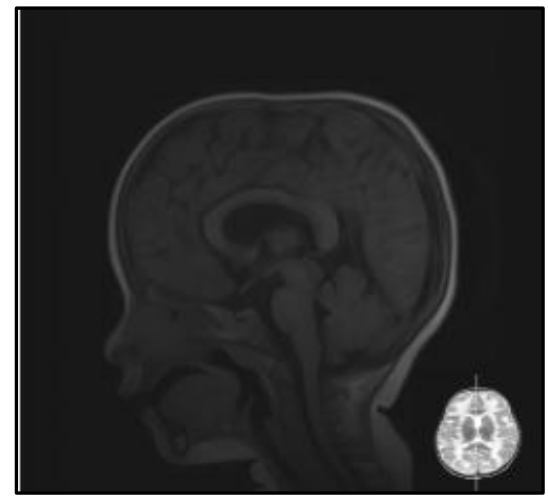

Fig. 5

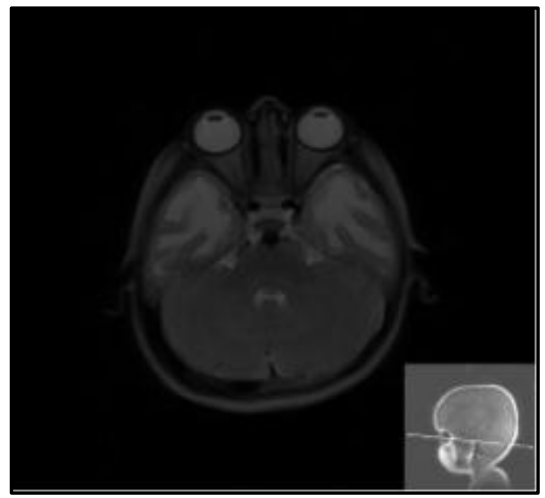

Fig. 6

Fig. 7: Axial T2WI at the level of basal ganglia shows the diffuse marked hyperintensity of the cortical white matter with sparing of the rostrum and splenium of the corpus callosum.

Fig. 8: Axial T2WI at the level of corona radiata shows the diffuse involvement of the cortical white matter.

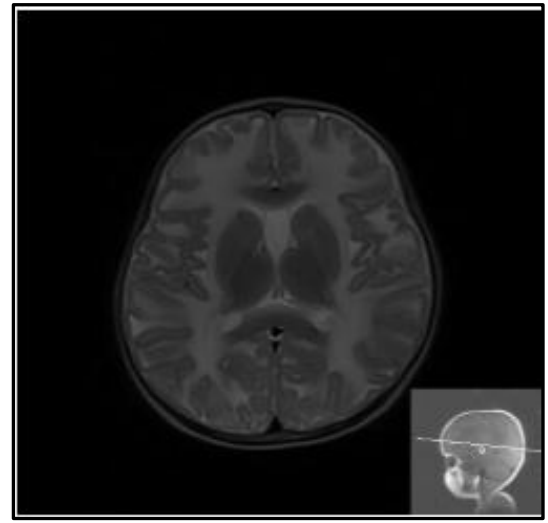

Fig. 7

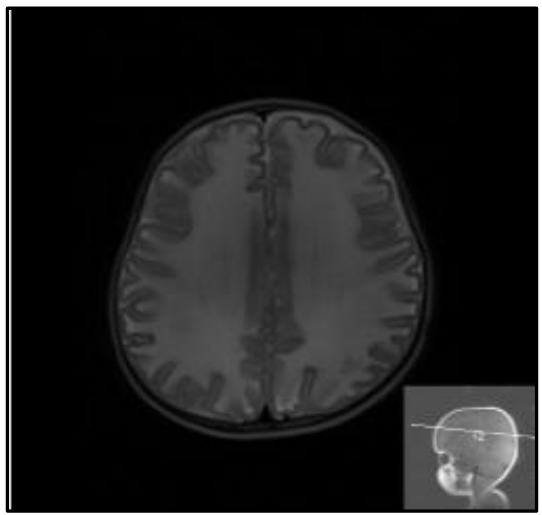

Fig. 8

DISCUSSION: MLC is a rare neurodegenerative disorder characterized by infantile-onset megalencephaly, cerebral leukoencephalopathy, and delayed onset of slowly progressive neurologic dysfunction. ${ }^{[2]}$ The megalencephaly typically develops during the 1st year of life. Initial mental capacities are normal, and motor development is mildly delayed in most patients.[3] Subsequently, slowly progressive ataxia and spasticity develops, although intellectual functioning is preserved for years after onset of the disorder.[4,5] In India, majority of the patients belong to the Agarwal community.[6,7] Our patient however did not belong to this community. Indian patients with megalencephaly and MR changes that show extensive white matter changes with temporal cysts should raise suspicion for MLC.[7] This disease has been assigned to the gene, MLC1, and is localized 
on chromosome 22qtel.[8] It has been reported that no basic biochemical defect was identified in patients with VML. Nonetheless de Stefano et al's 1H MR spectroscopy study involving two patients showed a significant decrease in NAA-Cr+phosphocreatine ratio and concomitant small increases in lactate in the white matter of both hemispheres.

Though Alexander disease, Canavan disease, and Glutaric aciduria have been considered as differential diagnosis of megalencephalic leukoencephalopathy with subcortical cysts, [9] these conditions are quite unlikely to have such a mild clinical course. None of these conditions have subcortical cysts on MRI and all of these involve basal ganglia unlike megalencephalic leukoencephalopathy with subcortical cysts.

\section{REFERENCES:}

1. Anne G. Osborn (2013). Osborn's brain: Imaging, Pathology and Anatomy. Canada: AMIRSYS. P 874-876.

2. Van der Knaap MS, Barth PG, Stroink H, et al. Leukoencephalopathy with swelling and a discrepantly mild clinical course in eight children. Ann Neurol 1995; 37: 324-334

3. Goutieres F, Boulloche J, Bourgeois M, Aicardi J. Leukoencepalopathy, megalencephaly, and mild clinical course: a recently individualized familial leukodystrophy: report on five new cases. J Child Neurol 1996; 11: 439-444.

4. Van der Knaap MS, Barth PG, Vrensen GF, Valk J. Histopathology of an infantile-onset spongioform leukoencephalopathy with discrepantly mild clinical course. Acta Neuropathol 1996; 92: 206-212.

5. Yakinci C, Soylu H, Kutlu NO, Sener RN. Leukoencephalopathy with a mild clinical course: a case report. Comput Med Imaging Graph 1999; 23: 169-172.

6. Topcu M, Saatci I, Topcuoglu MA, et al. Megalencephay and leukodystrophy with mild clinical course: a report on 12 new cases. Brain Dev 1998; 20: 142-153.

7. Gorospe JR, Singhal BS, Kainu T, Wu F, Stephan D, Trent J, Hoffman EP, Naidu S. Indian Agarwal megalencephalic leukodystrophy with cysts is caused by a common MLC1 mutation. Neurology. 2004 Mar 23; 62(6): 878-82.

8. Pascual-Castroviejo I, van der Knaap MS, Pronk JC, Garcia-Segura JM, Gutierrez-Molina M, Pascual-Pascual SI. Vacuolating megalencephalic leukoencephalopathy: 24 year follow-up of two siblings.Neurologia. 2005 Jan-Feb; 20(1): 33-40.

9. Singhal BS, Gorospe JR, Naidu S. Megalencephalic leukoencephalopathy with subcortical cysts. J Child Neurol. 2003; 18: 646-52. 


\section{CASE REPORT}

\section{AUTHORS:}

1. Ishaan Jani

2. V. D. Aironi

3. Ashutosh Chitnis

4. Priti Kapoor

5. Abhay Gursale

\section{PARTICULARS OF CONTRIBUTORS:}

1. $3^{\text {rd }}$ Year Junior Resident, Department of Radio-Diagnosis, M. G. M. Medical College \& Hospital, Navi Mumbai.

2. Associate Professor, Department of Radio-Diagnosis, M. G. M. Medical College \& Hospital, Navi Mumbai.

3. Associate Professor, Department of Radio-Diagnosis, M. G. M. Medical College \& Hospital, Navi Mumbai.

\section{FINANCIAL OR OTHER} COMPETING INTERESTS: None
4. Associate Professor, Department of RadioDiagnosis, M. G. M. Medical College \& Hospital, Navi Mumbai.

5. Professor, Department of Radio-Diagnosis, M. G. M. Medical College \& Hospital, Navi Mumbai

\section{NAME ADDRESS EMAIL ID OF THE CORRESPONDING AUTHOR:}

Dr. Ishaan Jani, 388/1101,

Sterling Heritage Bldg, Shankar Mattham Road, Matunga Mumbai-400019.

E-mail: ishaanjani@yahoo.in

Date of Submission: 13/06/2015.

Date of Peer Review: 15/06/2015.

Date of Acceptance: 13/07/2015.

Date of Publishing: 27/07/2015. 